\title{
Effects of temperature, phase type and timing, location, and human density on plant phenological responses in Europe
}

\author{
Nicole Estrella ${ }^{1, *}$, Tim H. Sparks ${ }^{2,3}$, Annette Menzel ${ }^{1}$ \\ ${ }^{1}$ Chair of Ecoclimatology, Technische Universitaet Muenchen, Am Hochanger 13, 85354 Freising, Germany \\ ${ }^{2}$ NERC Centre for Ecology and Hydrology, Monks Wood, Abbots Ripton, Huntingdon, \\ Cambridgeshire PE28 2LS, UK \\ ${ }^{3}$ Present address: 68 Girton Road, Girton, Cambridge CB3 0LN, UK
}

\begin{abstract}
Phenological onset dates are closely linked to temperature. In this study, we analysed a phenological dataset collected during the COST 725 Action 'Establishing a European phenological data platform for climatological applications', which contained more than 36000 phenological time series for Europe covering 1971-2000. We analysed the temperature response of the phenological phases, their regional differences, and the relationship between the sizes of the local temperature and phenology trends in connection with a high-resolution climate grid of Europe. As an external factor, we examined the influence of human population density on phenology. Our analyses confirm differences in behaviour between annual and perennial plants in Europe. The average temperature response of perennial plants was significantly greater $\left(-4.2 \mathrm{~d}^{\circ} \mathrm{C}^{-1}\right)$ than that of annual agricultural crops $\left(-3.0 \mathrm{~d}^{\circ} \mathrm{C}^{-1}\right)$. The correlation between temperature and phenology trends was greatest for leaf unfolding of fruit trees and deciduous trees $(\mathrm{r}=-0.63$ and -0.46 , respectively). The geographic coordinates (latitude and longitude) had only a modest influence on the mean onset of the groups of phases; however, inclusion of altitude improved the models for some groups.
\end{abstract}

KEY WORDS: Climate impacts $\cdot$ Phenology $\cdot$ Population density $\cdot$ Temperature response

\section{INTRODUCTION}

The latest IPCC report confirmed that the global climate has changed in recent decades and that this change has affected the Earth's natural resources (IPCC 2007). Most of the observed physical and biological systems have displayed a change in the expected direction (Rosenzweig et al. 2008). In Europe, there has been a long tradition of collecting onset dates for various plant phenological phases. Menzel et al. (2006) analysed a large dataset of Europe-wide phenological observations and showed that there has been a wide and convincing change in phenology over the last 3 decades of the 20th century towards earlier onset dates for spring phases and a slightly later onset of leaf colouring in autumn.
Several studies have shown significant correlations between spring or summer temperatures and the onset of phenological phases such as bud burst, leaf unfolding or flowering in mid and higher latitudes (Defila \& Clot 2001, Sparks \& Menzel 2002, Walther et al. 2002, Root et al. 2003, Menzel et al. 2006, Estrella et al. 2007), but autumn phases correlated less strongly with air temperature (Matsumoto et al. 2003, Estrella \& Menzel 2006, Menzel et al. 2006).

In general, the start of early, mid and late spring in Europe begins in the southwest and spreads to the northeast, while the summer spreads from south to north (Menzel et al. 2005b). This pattern changes depending on the North Atlantic Oscillation (NAO) index. In years with a high winter NAO, spring phenological phases spread from the southwest to the north- 
east; in years with a low winter $\mathrm{NAO}$, these spring phases follow a more south to north movement, having a greater latitudinal gradient than in high-NAO years (Menzel et al. 2005b). The speed of the 'green wave' has been quantified as $44 \mathrm{~km} \mathrm{~d}^{-1}$ from south to north and $200 \mathrm{~km} \mathrm{~d}^{-1}$ from west to east (Rötzer \& Chmielewski 2001).

The trends and the variability of early phenological phases are greater than those of later phases. For Germany and other parts of Europe, regional maps displaying the distribution of phenological trends have been created (e.g. Chmielewski \& Rötzer 2000, Menzel 2000, Ahas et al. 2002, Menzel et al. 2006).

Because of the close relationship between phenological onset and temperature, it follows that trends in phenology and in the triggering temperatures should also be connected. The response of plants to temperature varies depending on the species and type of plant; annual crops in Germany, for example, exhibited a lower temperature response to mean spring temperature than perennial crops (Estrella et al. 2007). This is in contrast to a study by Fitter \& Fitter (2002, in the UK) that concluded that the advancement of the onset of flowering was stronger in annual plants than in congeneric perennials, and in insect-pollinated species than in wind-pollinated ones. Even within the same species, there may be differences in shifts between the different phases such as the beginning and end of flowering, which may modify ecological interactions (Doi et al. 2008).

The magnitude of the temperature response varies greatly. For Germany, an analysis of long-term series (1900-2000) found that the advancement in the onset of flowering (horse chestnut, lilac, red currant) was between 2.6 and $6.9 \mathrm{~d}^{\circ} \mathrm{C}^{-1}$ (Menzel et al. 2005a). Another study covering all spring, summer and early autumn phases of wild plants in Germany revealed a temperature response between 4.2 and $6.7 \mathrm{~d}^{\circ} \mathrm{C}^{-1}$ (Menzel 2003). In Hungary, the temperature response of Robinia pseudoacacia L. flowering was $7 \mathrm{~d}^{\circ} \mathrm{C}^{-1}$ (Walkovszky 1998). For agricultural plants in Germany, the mean response to March-May temperature was $4.3 \mathrm{~d}^{\circ} \mathrm{C}^{-1}$ (Estrella et al. 2007).

The foregoing examples show that responses to temperature vary greatly, depending on phase and species. In general, earlier phases in the year show stronger responses to temperature than later phases. However, some development stages of plants need a certain time/amount of chilling before they can respond to forcing by warmth. Leaf unfolding of deciduous trees depends on winter chilling to break dormancy. Vernalisation of seeds of winter crops can only start after cold and frosty periods. Some phases, particularly in northern regions, are not triggered by warm temperatures alone, but also depend on photoperiod length and the fulfillment of a chilling requirement. Therefore, some phenological phases might even occur later if, due to warm winter temperatures, their chilling requirement has not been satisfied or day length has not exceeded a specific threshold. The lower temperature threshold is determined by plant physiology; below the threshold, no development proceeds. Relevant threshold temperatures found in the literature are between 5 and $10^{\circ} \mathrm{C}$. Therefore, temperature is the major factor influencing plant phenology in temperate regions. Human action influences temperature, and this is revealed in phenology via strong temperature and phenological differences between urban and rural areas (Landsberg 1981, Bernhofer 1991, Rötzer et al. 2000, Zhang et al. 2004). Because the magnitude of the urban heat island effect is influenced by the number of inhabitants in the area (Oke 1973), population density could also influence the phenological response.

Our aim in the current study is to analyse, on a European scale, the differences in the behaviour of phenological phases based on station data. We focus on (1) the temperature response of phenological phases and their regional patterns, (2) the relationship between local temperature and phenological trends, and (3) the influence of human population density.

\section{DATA AND METHODS}

\subsection{Data}

\subsubsection{Climate data}

Meteorological data were downloaded from the Climatic Research Unit website (www.cru.uea.ac.uk/cru/ data/hrg/cru_ts_2.10/). We selected the high-resolution $0.5 \times 0.5^{\circ}$ climate grid CRU TS 2.1 (Mitchell \& Jones 2005). This results in 4400 grid cells for Europe. We used monthly mean air temperature from 1971-2000 for our analyses. Information on the mean altitude of grid cells was used to calculate altitude-adjusted temperatures for the phenological stations contained in the cells. The height difference between the phenological station and the cell mean was taken into account; if the difference was $>150 \mathrm{~m}$, the temperature was corrected using:

$$
\begin{aligned}
T_{\text {st }}= & T_{\text {cell }}+[0.006 \mathrm{~K} \times(\text { mean cell altitude } \\
& - \text { phenological station altitude })]
\end{aligned}
$$

\subsubsection{Phenological data}

A dataset of phenological observations in Europe has been created within the COST 725 Action 'Establishing a European phenological data platform for climato- 
logical applications' (www.cost725.org), which comprised all phenological records from participating countries that were digitally available and uploaded before 2008. The selection criterion for our analyses was a minimum of 20 yr of observations within 19712000, and suitable data were available for 34651 series from a total of 19 countries (Table 1).

The distribution of phenological stations in Europe is very uneven, with a disproportionately high number being situated in Germany. Phenological phases of wild plants, fruit trees and agricultural crops were assigned a $\mathrm{BBCH}$ (Biologische Bundesanstalt, Bundessortenamt and CHemical Industry) code (Maier 1997) and grouped either by BBCH code or BBCH subgroup (principal growth stages). A total of 160 different codes were listed in the data, with some of them being observed at only one station. Each observation station was linked to the climate data of the grid cell in which it occurred.

\subsubsection{Data on human population density}

Tabulated data on human population density were downloaded from Euro Stat (REG_D3DENS; http:// epp.eurostat.ec.europa.eu/portal/page/portal/eurostat/ home). The population density of 1930 geopolitical regions (Nomenclature of Territorial Units for Statistics, NUTS 2) are included. Data were available as an ESRI (Environmental Systems Research Institute) shape file. Each phenological station was assigned to the closest shape cell.

Table 1. Countries in the phenological dataset, and number of codes, stations and total observational series used in analyses

\begin{tabular}{|lccc|}
\hline Country & Codes & Stations & Series \\
\hline Austria & 36 & 21 & 253 \\
Belgium & 3 & 3 & 4 \\
Croatia & 14 & 1 & 14 \\
Czech Rep. & 5 & 31 & 66 \\
Denmark & 3 & 1 & 3 \\
Finland & 7 & 3 & 9 \\
France & 2 & 3 & 3 \\
Germany & 84 & 1252 & 33065 \\
Ireland & 11 & 4 & 20 \\
Latvia & 17 & 3 & 34 \\
Lithuania & 47 & 14 & 324 \\
Luxemburg & 5 & 1 & 5 \\
Macedonia & 1 & 1 & 1 \\
Norway & 15 & 4 & 26 \\
Poland & 4 & 1 & 4 \\
Slovakia & 4 & 1 & 4 \\
Slovenia & 72 & 15 & 524 \\
Spain & 22 & 3 & 22 \\
Switzerland & 17 & 85 & 270 \\
\hline
\end{tabular}

\subsection{Methods}

Analyses were done for each station and all available phases. However, different countries and networks observed different species and phases. Thus, only a few phases were recorded in several countries. To enable comparison, we grouped phases into 6 classes: (1) agricultural crops, (2) deciduous trees, (3) wild shrubs/flowers, (4) conifers, (5) fruit trees, and (6) permanent grassland. Phases were characterized by their type and onset season into: (1) leaf unfolding/needle appearance/spring sprouting, (2) flowering, (3) fruiting, (4) leaf/needle colouring, (5) sowing, (6) growth stages of cereals, and (7) harvest. Phases 5 and 7 are considered 'false' phases, since farmers decide the date of the phase (see Table 5 for numbers of series and stations within each group).

In addition to single-station analysis, we also analysed cell means for the groups of classes and phases to reduce the influence of outliers.

Moreover, analyses were done by grouping all series by their mean onset date (seasonally and monthly). For correlation analysis, the results for each station were then averaged for each season and month.

\subsubsection{Trends and temperature response of phases}

For analyses, we used the deviation of the onset date for a phenological station from the mean of the grid cell for a particular phase for the period 1971-2000. This dataset was used to calculate the linear trend of the time series as well as the temperature responses. Trends in mean temperature were calculated for all months and for the 4 seasons-winter (DJF), spring (MAM), summer (JJA), autumn (SON) - for each grid cell containing phenological data, by linear regression on year. Trends for each phenological series were calculated by linear regression of phenological onset dates on year. Phenological responses to temperature were calculated by linear regression of phenological onset dates on the mean monthly temperatures of the preceding months as well as the seasonal temperatures of the preceding winter, spring and summer. The selection criterion for further analysis was the $\mathrm{R}^{2}$ of the regression. Selection was made by ranking all regressions on the preceding months' temperatures (from December of the preceding year up to the month when the mean onset day of a particular phase occurred) by their $\mathrm{R}^{2}$. The temperature response was taken as the slope of the regression of the onset date of a particular phenological phase on the monthly mean temperature with the highest $\mathrm{R}^{2}$. Trends in phenology for each station within a grid cell were compared to trends in temperature for the same grid cells using 
Pearson's correlation coefficients: (1) we compared all phenological trends of each station with temperature trends of the selected months (i.e. the months with the highest $\mathrm{R}^{2}$ ) of the grid cell; (2) as seasonal mean of phenological trends of the grid cell with the corresponding seasonal temperature trend; (3) this was repeated using monthly averages of the grid cell for phenological trends that were correlated with the temperature trend of the grid cell of the preceding month.

\subsubsection{Geographic influences}

The geographic influences on onset dates and trends were calculated by multiple regression of the average onset dates and trends of groups of phases against latitudinal and longitudinal coordinates (where regression coefficients indicate gradients in number of days per degree of latitude or longitude), as well as altitude (where the regression coefficient signifies the delay per metre). It should be remembered that the distance represented by $1^{\circ}$ of longitude decreases from the equator to the poles; e.g. $1^{\circ}$ longitude corresponds to $85 \mathrm{~km}$ at $40^{\circ} \mathrm{N}$ compared to $47 \mathrm{~km}$ at $65^{\circ} \mathrm{N}$. We also examined Pearson's correlation coefficients between the geographic coordinates of the observation site and both the phenological trends and the mean onset dates of a particular phase. We eliminated groups of phases that were represented by $<200$ stations. To further analyse the influence of the geographic position of the station on results, we divided Europe into 6 latitudinal zones as listed in Table 2 . To identify altitudinal differences in temperature response within groups of phases, the latter were grouped by station altitude.

\subsubsection{Human population density and phenological trends}

The influence of population density on the sizes of the mean phenological onset dates and trends were examined by calculating Pearson's correlation coefficients. In cases where $>1$ shape cell was at the same distance from the phenological station, the minimum, maximum and mean population sizes were used for comparison with the mean phenological trends and onset dates.

\section{RESULTS}

\subsection{Temperature response}

Most of the temperature responses (regression coefficients) (92\%) had a negative sign, the overall mean for Europe being $-3.78 \mathrm{~d}^{\circ} \mathrm{C}^{-1}$, with data ranging from
Table 2. Latitudinal grouping of stations and number of stations within each group

\begin{tabular}{|llcc|}
\hline Code & Group & Lat. $\left({ }^{\circ} \mathrm{N}\right)$ & No. of stations \\
\hline $\mathrm{N}$ & Northern Europe & $>54$ & 630 \\
$\mathrm{CN}$ & Northern Central Europe & $52-54$ & 4745 \\
$\mathrm{CMN}$ & $\begin{array}{c}\text { Northern part of } \\
\text { mid-Central Europe }\end{array}$ & $50-52$ & 11398 \\
$\mathrm{CMS}$ & $\begin{array}{l}\text { Southern part of } \\
\text { mid-Central Europe }\end{array}$ & $48-50$ & 12871 \\
$\mathrm{CS}$ & $\begin{array}{l}\text { Southern Central Europe } \\
\mathrm{S}\end{array}$ & $46-48$ & 4480 \\
& Southern Europe & $<46$ & 527 \\
\hline
\end{tabular}

-22.13 (for Corylus avellana flowering in the northern region) to $8.88 \mathrm{~d}^{\circ} \mathrm{C}^{-1}$ (for a growth stage of Triticum aestivum in winter in the southern part of central middle Europe, CMS). Most slopes (60\%) were between -1.3 and $-5.1 \mathrm{~d}^{\circ} \mathrm{C}^{-1}$.

We created histograms for each group of phases classified by region (Appendix 1) to show the distribution of the temperature response. Some groups had few or no positive responses. These groups are leaf/ needle unfolding of agricultural crops, deciduous trees, fruit trees, and conifers; flowering of fruit trees, deciduous trees, and wild shrubs/flowers; and growth stages of agricultural crops. The highest proportion of positive temperature responses, as expected, was noted for leaf colouring of deciduous trees. In histograms displaying relative frequencies for the different regions, these patterns vary because the dominating stations of central Europe lose importance. The modal classes for the response rates of leaf unfolding of deciduous trees lie within the $-3 \mathrm{~d}^{\circ} \mathrm{C}^{-1}$ band, within the $-4 \mathrm{~d}{ }^{\circ} \mathrm{C}^{-1}$ band for conifer needle development, and within the $-5 \mathrm{~d}{ }^{\circ} \mathrm{C}^{-1}$ band for fruiting of fruit trees. The distribution of temperature responses for the following groups is characterized by a less distinct modal response: fruit tree leaf unfolding, deciduous tree flowering, deciduous tree fruiting and agricultural crop harvest. These groups have a high proportion of responses that were below $-4 \mathrm{~d}{ }^{\circ} \mathrm{C}^{-1}$. The 'false' phase, agricultural crop sowing, exhibited the least temperature responses; almost $40 \%$ are between -3 and $-1 \mathrm{~d}{ }^{\circ} \mathrm{C}^{-1}$. The main exception is leaf colouring of deciduous trees; this autumn phase has $>50 \%$ positive responses. Northern stations often respond more strongly to higher temperatures, with the distribution of response rates for the flowering of fruit and deciduous trees as well as leaf unfolding and fruiting of deciduous trees tending to be more negative. More southern stations also seem to respond differently to temperature, although the number of available stations is too low to be conclusive. The regions in central Europe show a more uniform pattern. 
Table 3. Linear trends per year of phenological $\left(\mathrm{P}, \mathrm{d} \mathrm{yr}{ }^{-1}\right)$ and temperature $\left(\mathrm{T},{ }^{\circ} \mathrm{C} \mathrm{yr}^{-1}\right)$ time series. Phenological phases are grouped seasonally by their mean onset day; N: number of phenological observations (P) and grid cells (T) containing phenological stations

\begin{tabular}{|c|c|c|c|c|c|c|c|c|}
\hline \multirow{2}{*}{ Season } & \multicolumn{2}{|c|}{$-\mathrm{N}$} & \multicolumn{2}{|c|}{ _ Trend _ } & \multicolumn{2}{|c|}{$\mathrm{SD}_{-}$} & \multicolumn{2}{|c|}{$\mathrm{SE}$} \\
\hline & $\mathrm{P}$ & $\mathrm{T}$ & $\mathrm{P}$ & $\mathrm{T}$ & $\mathrm{P}$ & $\mathrm{T}$ & $\mathrm{P}$ & $\mathrm{T}$ \\
\hline Spring (Mar, Apr, May) & 17834 & 302 & -0.338 & 0.027 & 0.285 & 0.011 & 0.0021 & 0.0007 \\
\hline Summer (Jun, Jul, Aug) & 7020 & 289 & -0.364 & 0.056 & 0.317 & 0.010 & 0.0038 & 0.0006 \\
\hline Autumn (Sep, Oct, Nov) & 8037 & 286 & -0.178 & 0.033 & 0.377 & 0.014 & 0.0042 & 0.0009 \\
\hline Winter (Dec, Jan, Feb) & 1760 & 241 & -0.425 & 0.021 & 0.394 & 0.012 & 0.0094 & 0.0008 \\
\hline Year & 34651 & 1118 & -0.326 & 0.034 & 0.357 & 0.012 & 0.005 & 0.001 \\
\hline
\end{tabular}

To confirm the visual impression, regional differences were tested using 1-way ANOVA. Results indicate that the region accounts for a significant portion of the variability in the temperature response for all but 2 groups of phases: fruiting of fruit trees and leaf colouring of deciduous trees. Comparison between the midcentral and the northern central region shows no significant difference in the distribution of temperature responses for 6 groups of phases (fruiting of fruit trees and of deciduous trees, growth stages of cereals, leaf colouring of deciduous trees, and harvest of permanent grassland and of agricultural crops).

Maps of mean values for each station were created for each group of phases; however, no regional pattern was identifiable (therefore not shown). The temperature sensitivity of flowering of wild trees in NW Germany was slightly higher than in the rest of Germany, and stations in Switzerland also demonstrated relatively high values.

We further grouped the stations by their altitude (not shown); most stations were situated between 250 and $500 \mathrm{~m}$ a.s.l., with only a few being above $750 \mathrm{~m}$ a.s.l. Differences between the altitudinal groups $(<100$, $100-250,250-500$ and 500-750 m) for most groups of phases (except for fruit trees leaf unfolding, where sample size was too small) were significant.

\subsection{Temporal trends of phenological phases and temperature}

The linear trends of all time series for the period 1971-2000 reveal a wide range of values. The European seasonal trends for phenology and temperature are listed in Table 3. Phenological series are grouped by their mean onset dates during the 4 seasons of the year. The trends confirm recent findings that the variability and trends are greatest early in the year (winter/early spring) and smaller in autumn. Trends of phenological events classified by the month of the mean onset date of the phase are shown in Appendix 2 . Events with average dates in February had a tendency for highly negative trends $\left(23 \%<-0.7 \mathrm{~d} \mathrm{yr}^{-1}\right)$ with a

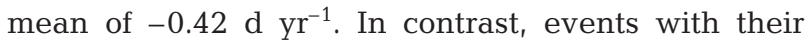
mean onset date in March tended to have less negative trends, with $24 \%$ having a positive sign, and the mean

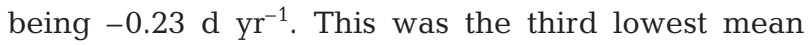

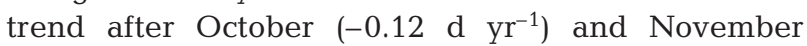
$\left(0.13 \mathrm{~d} \mathrm{yr}^{-1}\right)$. For autumn months, we expect positive trends, i.e. later leaf colouring and a lengthening of the growing season.

The mean phenological trend for each season was negative, indicating an earlier onset towards the end of the time series, although some positive trends existed in all seasons. More than half of the series in our dataset were in spring and $<5 \%$ were in winter. For temperature, the mean trend was highest for summer $\left(0.56^{\circ} \mathrm{C}\right.$ decade $\left.^{-1}\right)$ and lowest for winter $\left(0.21^{\circ} \mathrm{C}\right.$ decade $\left.^{-1}\right)$.

Fig. 1a shows the distribution of the mean phenological trend in spring for each station. Overall, most stations reveal negative trends, but most Czech stations have a positive trend in spring. Looking at the spring temperature trend of the corresponding grid cells (Fig. 1b) shows that this pattern fits the phenological trends, i.e. very weak, no or slightly negative temperature trends in the Czech Republic.

The highest correlation (based on cell means of phenological trends of -0.42) between phenological and temperature trends (Table 4) was achieved in spring. Correlation coefficients declined over the remainder of the year and were not significant for autumn and winter. This pattern was also apparent when considering phenological trends at the station level, but the winter coefficient was particularly low.

A correlation between the temperature trend of the preceding month and the phenological cell mean trend grouped by their monthly onset date was calculated. Here, the highest coefficients were found for mean onset dates in March (-0.37; correlated with the temperature trend of February) and April (-0.58; correlated with the temperature trend of March)

A further analysis was made by splitting the data into groups of phases for each cell. The correlation coefficients between temperature and phenological trends of the groups are listed in Table 5; only classes 

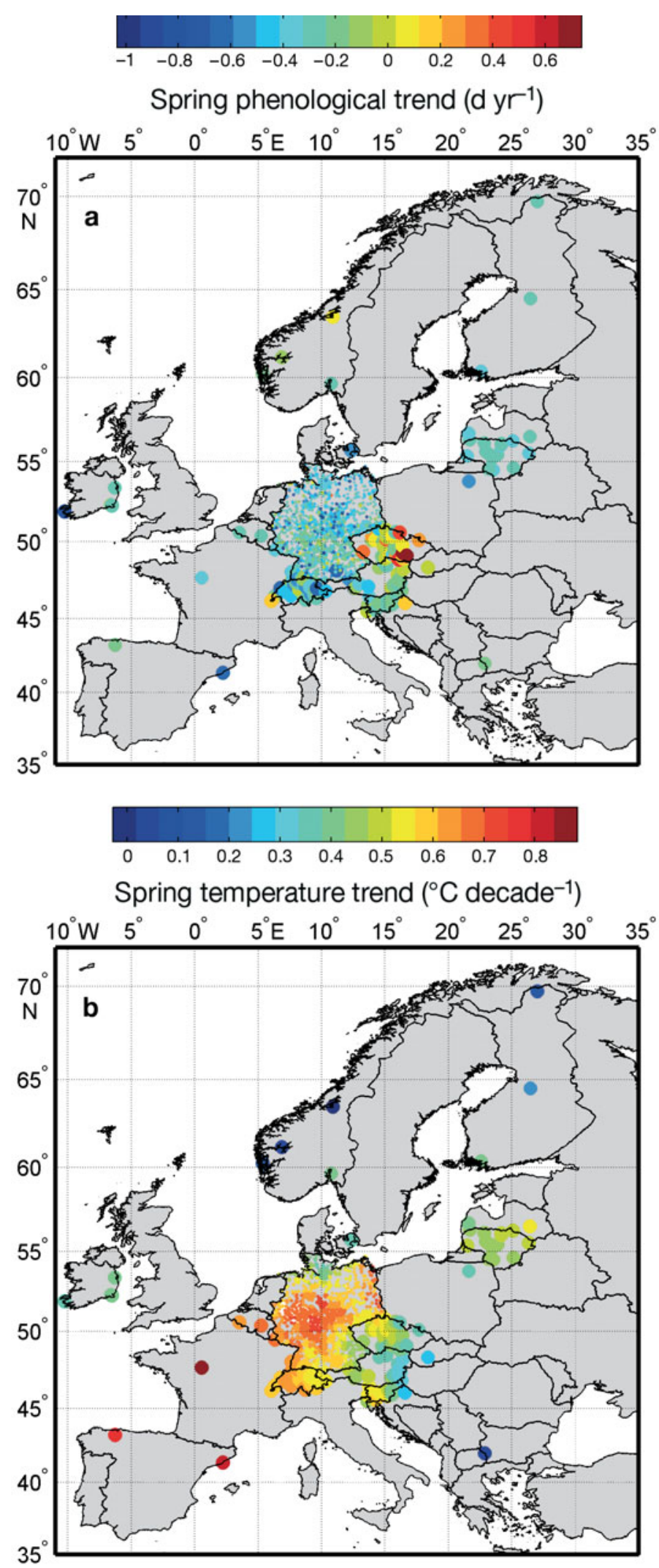

Fig. 1. Spring trends of (a) phenology and (b) temperature in Europe. Each dot represents the mean for spring at a station. Dot size adjusted for clarity
Table 4. Correlation between phenological and temperature trends (bold: $\mathrm{p}<0.01)$. The number of series $\left(\mathrm{N}_{\text {series }}\right)$ and occupied grid cells $\left(\mathrm{N}_{\text {cell }}\right)$ and the correlation between trends of phenology and temperature are averaged by either grid cells ( $\left.\mathrm{r}_{\text {cell }}\right)$ or stations $\left(\mathrm{r}_{\text {station }}\right)$

\begin{tabular}{|lcccr|}
\hline Season & $\mathrm{N}_{\text {cell }}$ & $\mathrm{N}_{\text {series }}$ & $\mathrm{r}_{\text {cell }}$ & $\mathrm{r}_{\text {station }}$ \\
\hline Spring & 302 & 17834 & $\mathbf{- 0 . 4 2}$ & $\mathbf{- 0 . 2 9}$ \\
Summer & 289 & 7020 & $\mathbf{- 0 . 1 7}$ & $\mathbf{- 0 . 2 6}$ \\
Autumn & 286 & 8037 & 0.08 & $\mathbf{- 0 . 2 6}$ \\
Winter & 241 & 1760 & 0.07 & $\mathbf{- 0 . 1 4}$ \\
\hline
\end{tabular}

covering $>20$ grid cells were included. The classes were assigned to a season based on the mean date of all observations, and none of the classes for this analysis belonged to winter. Some classes reveal strong negative significant relationships between the trends for temperature and phenology; leaf unfolding of fruit and deciduous trees and agricultural crops had the highest correlations $(-0.63,-0.46,-0.39)$, followed by needle appearance of conifers $(-0.36)$, flowering of fruit trees $(-0.34)$, and growth stages of agricultural plants and fruiting of deciduous trees $(-0.33)$. All other classes had smaller negative correlation coefficients $(-0.3$ to 0$)$.

\subsection{Geographic influence on the phenological onset dates and trends}

The regression of mean onset dates for groups of phenological phases on geographic coordinates and altitude was significant for 9 of 14 groups; 4 groups were influenced by 2 of the 3 parameters. Only 1 group (leaf unfolding of agricultural crops) showed no influence of latitude and longitude but only of altitude. The largest coefficient of determination $\left(\mathrm{R}^{2}\right)$ was for agricultural crops leaf unfolding $(0.54)$, followed by deciduous trees leaf unfolding $(0.47)$, needle appearance of conifers (0.36), harvest of permanent grassland (0.36), and fruiting of deciduous trees $(0.23) ; \mathrm{R}^{2}$ was $<0.15$ for all other groups.

Almost all groups of phases developed from the south towards the north, with some having a west to east component (e.g. fruiting of deciduous trees), others having an east to west component (e.g. harvest of agricultural crops), and still others being more or less straight (e.g. deciduous trees leaf unfolding). As expected, leaf colouring of deciduous trees spread from the northeast towards the west southwest. Two groups (agricultural crops sowing, fruit trees flowering) revealed a north to south gradient, but with a low $\mathrm{R}^{2}$. The regression coefficients for leaf colouring were negative for latitude, longitude and altitude, indicating that the development of this phase starts in the 
Table 5. Correlation between the trends of the groups of phenological phases and temperature, and their mean temperature responses (mean regression). $\mathrm{N}_{\text {series }}$ : total number of series for the groups of phases, $\mathrm{N}_{\text {station }}$ : number of stations for the groups. Also given are the mean onset dates of the groups of phases, the season in which they occur and the mean trends of the groups. DOY: day of year. Correlations in bold are significant $(\mathrm{p}<0.01)$

\begin{tabular}{|c|c|c|c|c|c|c|}
\hline Groups of phases & $\mathrm{N}_{\text {series }}$ & $\mathrm{N}_{\text {station }}$ & $\mathrm{r}$ & $\begin{array}{c}\text { Mean regression } \\
\left(\mathrm{d}^{\circ} \mathrm{C}^{-1}\right)\end{array}$ & $\begin{array}{l}\text { Mean trend } \\
\left(\mathrm{d} \mathrm{yr}^{-1}\right)\end{array}$ & $\begin{array}{l}\text { Mean onset } \\
\text { (DOY) }\end{array}$ \\
\hline \multicolumn{7}{|l|}{ Spring } \\
\hline Wild shrubs/flowers flowering & 3996 & 1225 & -0.23 & -4.13 & -0.28 & 101 \\
\hline Deciduous trees flowering & 7910 & 1293 & -0.24 & -5.41 & -0.47 & 114 \\
\hline Fruit trees leaf unfolding & 61 & 52 & -0.63 & -4.45 & -0.40 & 115 \\
\hline Deciduous trees leaf unfolding & 4139 & 1184 & -0.46 & -3.66 & -0.34 & 117 \\
\hline Conifers needle development/may shoot & 1252 & 853 & -0.36 & -4.25 & -0.39 & 119 \\
\hline Fruit trees flowering & 963 & 679 & -0.34 & -4.25 & -0.34 & 122 \\
\hline Agricultural crops leaf unfolding & 338 & 338 & -0.39 & -2.05 & -0.16 & 124 \\
\hline Conifers flowering & 1 & $<20$ & & & & 136 \\
\hline \multicolumn{7}{|l|}{ Summer } \\
\hline Permanent grassland harvest & 606 & 606 & -0.16 & -3.28 & -0.19 & 154 \\
\hline Agricultural crops sowing & 2899 & 780 & -0.19 & -2.24 & -0.10 & 171 \\
\hline Agricultural crops flowering & 15 & $<20$ & & & & 174 \\
\hline Agricultural crops growth stages phases & 2994 & 752 & -0.33 & -3.16 & -0.34 & 197 \\
\hline Fruit trees fruiting & 2042 & 856 & -0.29 & -4.40 & -0.37 & 221 \\
\hline Agricultural crops harvest & 1905 & 783 & -0.04 & -4.54 & -0.24 & 230 \\
\hline \multicolumn{7}{|l|}{ Autumn } \\
\hline Deciduous trees fruiting & 2693 & 1073 & -0.33 & -4.27 & -0.38 & 250 \\
\hline Deciduous trees leaf colouring & 2815 & 1067 & -0.04 & 0.18 & 0.02 & 282 \\
\hline Fruit trees leaf colouring & 18 & $<20$ & & & & 289 \\
\hline Conifers needle colouring & 4 & $<20$ & & & & 299 \\
\hline
\end{tabular}

northeast and at higher elevation and spreads towards the southwest and lower regions. The mean onset of harvest of agricultural crops and permanent grassland follows a southeast to northwest direction.

However, the regional distribution of the mean trend for groups of phases was influenced rather less by the geographic position of the station; only the following groups showed a significant influence of latitude, longitude and altitude on their mean trends: sowing, growth stages and harvest of agricultural crops, leaf unfolding and flowering of deciduous trees, and flowering of wild flowers/shrubs. For all groups, $\mathrm{R}^{2}$ was $<0.10$.

\subsection{Human population density and phenological onset dates and trends}

The best results in the correlation analysis was obtained between the minimum population density and the mean onset date of the groups of phases. The sign of the correlation coefficient was in the expected direction for almost all groups of phases, i.e. negative except for leaf colouring of deciduous trees and harvest of agricultural crops. Thus, a higher population density was associated with earlier onset dates. The expected positive relationship with leaf colouring was observed; higher density was associated with a delay in leaf colouring. The mean date of harvest of agricultural crops showed no significant correlation with pop- ulation density. Fig. 2 shows 2 selected boxplots of the mean onset dates for flowering of wild shrubs and flowers and leaf colouring of deciduous trees against population density grouped in classes.

A significant relationship between population density and both the phenological trends and temperature responses of the groups of phases could not be detected. The coefficient of determination was $<0.015$ for all regression equations.

\section{DISCUSSION}

Analyses were done on grouped data using different criteria. Such grouping is not ideal, and may mask some features, but we feel it was necessary to deal with such heterogeneous data. The method of grouping phenological data by the plant characteristics and similar development stages provides an opportunity to compare phenological differences. Of course, there was high variability within these groups, but this variability can also be found within species-specific phenological phases as well (e.g. Ahas 1999, Menzel et al. 2001, Estrella \& Menzel 2006). The temperature response of the groups of phases reflects the expected results. Leaf colouring of deciduous trees in autumn responded to warmer temperatures with an average delay of $0.18 \mathrm{~d}^{\circ} \mathrm{C}^{-1}$. This is a weaker response than the $1 \mathrm{~d}^{\circ} \mathrm{C}^{-1}$ reported by Menzel et al. (2006). A closer look reveals a 


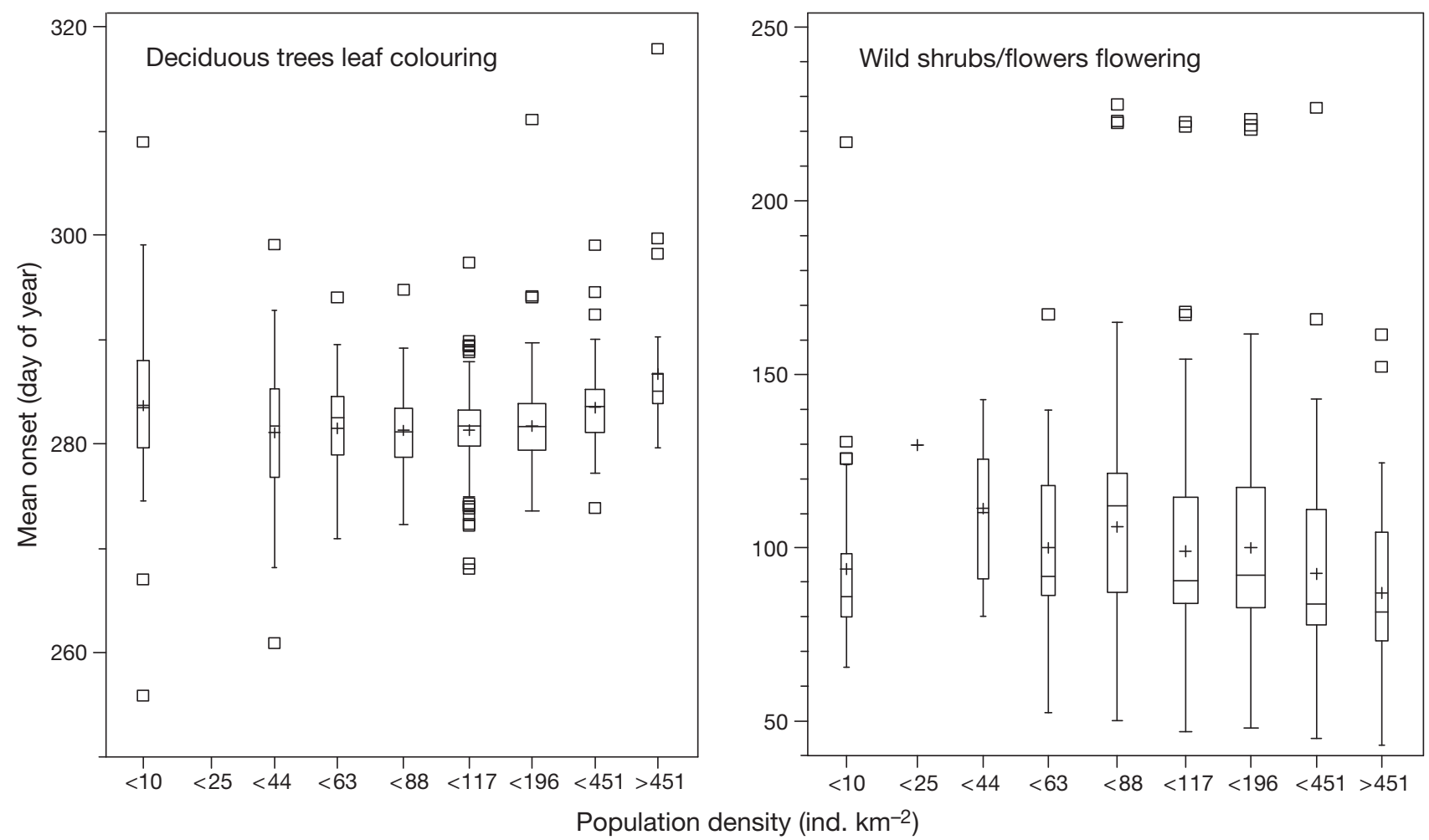

Fig. 2. Onset dates for sample groups of phases against human population density grouped into 9 classes. The box represents the interquartile range (IQR) with whiskers extending to a maximum of $\pm 1.5 \times \mathrm{IQR}$. Within each box: (horizontal line) median, (plus) mean, (squares beyond whiskers) outliers. The width of the box varies proportionately with group size

wide range of responses for this phase, with $56 \%$ being positive. In addition, 738 out of the 2815 series are for leaf colouring of Aesculus hippocastanum. Due to the invasion of a pest (cf. Menzel et al. 2008), this tree species can exhibit an earlier onset of leaf colouring and respond negatively to warm temperatures $\left(-0.8 \mathrm{~d}^{\circ} \mathrm{C}^{-1}\right)$. Excluding this species modifies the mean response to $0.54 \mathrm{~d}^{\circ} \mathrm{C}^{-1}$. For other groups of phases, our mean temperature responses are larger than those of other studies. The greatest mean response was for flowering of deciduous trees $\left(-5.41 \mathrm{~d}^{\circ} \mathrm{C}^{-1}\right)$. Most groups of phases had mean responses that were $>-3 \mathrm{~d}^{\circ} \mathrm{C}^{-1}$ (except for leaf unfolding of agricultural crops $\left(-2.05 \mathrm{~d}^{\circ} \mathrm{C}^{-1}\right)$ and, as mentioned above, leaf colouring of deciduous trees. Menzel et al. (2006) reported mean responses of around $-2 \mathrm{~d}^{\circ} \mathrm{C}^{-1}$ for Europe. This difference may be because we did not calculate country means, so every station had the same weight.

The group with the second highest proportion of positive responses to temperature is the 'false' phase, sowing of agricultural crops, where $11 \%$ of the values were positive. All groups of phases of agricultural crops including harvest of grassland had a proportion of positive responses that were $>5 \%$, whereas phases of wild shrubs and flowers, deciduous trees, fruit trees and conifers had very few or no responses with positive signs. Agricultural plants are strongly affected by management practices and plant breeding; thus, even natural phases such as leaf unfolding showed a lower response to temperature than in wild plants. Due to breeding selection, these economic plants seem to react less and more uniformly to temperature. Furthermore, our results show the different behaviour of perennial and annual agricultural plants. These results confirm our analyses of the agricultural phenological data for Germany (Estrella et al. 2007), in which we calculated temperature responses at the national level and showed that perennials had a significantly higher response to spring temperatures than annual crops.

Regional differences shown as stronger temperature responses at stations further north indicate a higher sensitivity to temperature due to the need to optimise vegetative stages under less favourable conditions.

Although most groups of phases showed the expected responses, biological systems sometimes react differently than expected, and some series show a positive temperature response even for phases that are mainly negative. We have some geographic information to compare with our dataset, but we do not have access to additional information (e.g. detailed site information, soil information, slope and exposition) to permit further examination of other influences. 
The trend analyses presented some expected as well as unexpected results. We expected strong trends in late winter, which would be associated with early spring phases in February that show the highest variability in their onset dates. However, the monthly distribution was not quite as expected, with March and April having weaker trends than May, June and July. One reason might be the inclusion of a high proportion of the 'false' phase, sowing of crops, in March and April, onset of sowing being determined by farmers. Other studies (e.g. Menzel et al. 2006, Estrella et al. 2007) have shown that these false phases show weaker trends than natural phases. In June, most of the phases were of flowering, which is sensitive to temperature. In May, flowering and leaf unfolding phases dominate, both natural phases being mainly dependent on temperature in temperate regions.

The distribution of correlations between the temperature trend of the preceding month and the phenological cell mean trend grouped by their monthly onset date was unexpected. Here, the highest coefficients for mean onset dates were found in March $(-0.37)$ and April (-0.58). Thus, a high proportion of anthropogenically influenced false phases seems to mirror the temperature trend. One reason for this might be the averaging of the trends for the grid cells, which might have led to a better match between temperature and phenological trends.

The seasonal temperature trends for grid cells containing phenological stations were strongest in summer and autumn and weakest in winter. This result contrasts with the temperature trends in Germany, where the highest trend was in spring and the lowest was in autumn and winter (Schönwiese et al. 2006). This may be due to the inclusion of additional grid cells of European countries for the analyses and the use of different German climate stations.

It is clear that the correlation is less strong when seasonal temperatures are used to explain phenology, because the temperature in the month before an event occurs is usually the decisive factor for phenology. However, we compared the results during the course of the year to identify behavioural similarities within these heterogeneous time series and found a good correlation between trends of spring phenological phases and trends of spring temperatures $(\mathrm{r}=$ -0.42), although the phenological trends during the other seasons were less related to the seasonal temperature trends. Menzel et al. (2006) reported the same results for country means, with the strongest correlation being found for spring phases, and the weakest being for autumn phases. One reason for the strong relationship at the beginning of the year is that phenological phases early in the year are more strongly triggered by temperature than later phases.
During the course of the year, other influencing factors such as water availability, nutrition and pollution may become important.

The regional pattern of phenology was tested by a regression between the onset of phenological phases and the geographic coordinates and altitude of the station. The geographic and altitudinal dependence of the mean onset dates was strong $\left(R^{2}>0.3\right)$ for 5 groups of phases, while a further 5 groups hardly seemed to be influenced by the altitude, longitude and latitude of the station $\left(\mathrm{R}^{2}<0.1\right) ; 4$ of the latter groups pertained to observed agricultural and cultivated (fruit trees) plants. These groups are strongly affected by breeding, so the cultivars observed here may be very important, although this information is not included within the data set.

Less than $10 \%$ of the trends can be explained by geographic coordinates and altitude. Thus, more research is needed to better define factors that influence the trends of phenological stations.

Another problem with the dataset is that different countries observed different plants and phases, thus grouping of these plants and phases was the only way to obtain supranational results. However, the number of series varied greatly between countries and some groups were not observed in some countries; thus, there might be a distortion in the results for some groups.

The relationship between population density and mean onset dates was only weak. The size of a city, the density of buildings or the proportion of hard sealed surfaces may be further factors that could influence temperature and thus phenology. Relationships between population density and phenological trends were even weaker. Further research on the influence of human population density on phenology is required.

\section{CONCLUSIONS}

The dataset analysed in this study allowed a European multinational analysis of phenological responses to temperature. To achieve locally valid results, we used a high-resolution temperature grid and summarized the results of the station-based regressions. This yielded a wide range of trends and temperature responses.

Menzel et al. (2006) described trends in European phenology in detail. In the current paper, we concentrated on the temperature response of the phenology, the relationship between the phenological and the temperature trends and tried to link one other external influence (population density) to phenological changes.

So far, no study has looked at an international analysis of stationwise phenological onset dates in combi- 
nation with a high-resolution temperature grid. The plants and phases had to be grouped to enable the use of the maximum number of grid cells. We grouped the data according to the character of the phenological phases and the plants into groups of phases. The database contained both cultivated and wild plants.

The groups reveal differences in their temperature responses. With one exception, responses tended to be negative, indicating an earlier start with warmer temperatures. This was, as expected, not true for leaf colouring of deciduous trees, which generally occurred later if the temperature increased.

Except for leaf colouring of deciduous trees, the response rates are slightly higher than in the study of Menzel et al. (2006). The response of perennial plants was significantly higher than that of annual crops $\left(-4.2\right.$ vs. $\left.-3.0 \mathrm{~d}^{\circ} \mathrm{C}^{-1}\right)$, confirming the results of Estrella et al. (2007).

Menzel et al. (2006) showed that the magnitudes of the temperature and phenological trends on a seasonal and country basis were linked. In the current study, we classified phenology into groups of plants and phases and analysed the relationship between the trends for the phenological stations and the temperature trends of the associated grid cells. The trends of phenology and temperature were linked for some groups and phases and were most correlated for leaf unfolding of wild trees, fruit trees and agricultural crops. For this analysis, none of the studied classes belonged to winter.

Additionally, the phenological trends were grouped according to their mean onset dates into seasons and months. The seasonal trends of phenology show the common pattern of high variability and strong response at the beginning of the year and lower trends for autumn. This indicates a declining influence of temperature through the course of the year. Within the monthly analyses, this pattern was interrupted due to numerous agricultural events - especially sowing of crops-leading to lower trends in March and April. The more uniform distribution of the phenological trends in these 2 months might explain the best correlation obtained with temperature trends of the previous month.

The regional distribution of temperature responses and trends could not be explained by geographic coordinates and altitude.

Although the grouping we used might not be suitable for analysing geographic dependence, it was suitable to show that the population density around the stations influenced the mean onset dates of the groups of phases. The size of the temperature difference in rural and urban areas is strongly influenced by the size of the settlement and the population (Oke 1973). Therefore, it was expected that population density would act as a driver of phenological change. Here, we related population density directly with the onset of the phenology. Human settlement seemed to cause phenology in densely populated areas to occur earlier than in less inhabited areas. The regression on population density was slightly negative for the mean onset dates for permanent grassland and positive for leaf colouring of deciduous trees. However, the correlation of the trends of groups of phenological phases with population density in Europe was weak.

To sum up, various methods and techniques could be used for the analyses of heterogeneous phenological data on a station basis. We selected the most suitable method and were able to confirm (1) that temperature and phenology trends in spring are linked, (2) the differences between annual and perennial plants, and (3) the differences between wild plants and agricultural plants.

Acknowledgements. We thank the COST 725 Action for providing the phenological data analysed in this work.

\section{LITERATURE CITED}

Ahas R (1999) Spatial and temporal variability of phenological phases in Estonia. PhD thesis, Tartu

Ahas R, Aasa A, Menzel A, Fedotova VG, Scheifinger H (2002) Changes in European spring phenology. Int J Climatol 22:1727-1738

Bernhofer C (1991) Stadtphänologie am Beispiel der Forsythia. Wetter Leben 43:213-218

Chmielewski FM, Rötzer T (2000) Phenological trends in Europe in relation to climatic changes. Agrarmeteorol Schr 7:1-15

Defila C, Clot B (2001) Phytophenological trends in Switzerland. Int J Biometeorol 45:203-207

Doi H, Gordo O, Katano I (2008) Heterogeneous intra-annual climatic changes drive different phenological responses at two trophic levels. Clim Res 36:181-190

- Estrella N, Menzel A (2006) Responses of leaf colouring in four deciduous tree species to climate and weather in Germany. Clim Res 32:253-267

> Estrella N, Sparks TH, Menzel A (2007) Trends and temperature response in the phenology of crops in Germany. Glob Change Biol 13:1737-1747

Fitter AH, Fitter RSR (2002) Rapid changes in flowering time in British plants. Science 296:1689-1691

IPCC (2007) Climate change 2007: impacts, adaptation and vulnerability. Contribution of Working Group II to the Fourth Assessment Report of the Intergovernmental Panel on Climate Change. Cambridge University Press, Cambridge

Landsberg JJ (1981) The urban climate. Academic Press, New York

Maier U (1997) Growth stages of mono- and dicotyledonous plants. Blackwell, Berlin

Matsumoto K, Ohta T, Irasawa M, Nakamura T (2003) Climate change and extension of the Ginkgo biloba L. growing season in Japan. Glob Change Biol 9:1634-1642

Menzel A (2000) Trends in phenological phases in Europe between 1951 and 1996. Int J Biometeorol 44:76-81

Menzel A (2003) Plant phenological anomalies in Germany 
and their relation to air temperature and NAO. Clim Change 57:243-263

Menzel A, Estrella N, Fabian P (2001) Spatial and temporal variability of the phenological seasons in Germany from 1951 to 1996. Glob Change Biol 7:657-666

Menzel A, Estrella N, Testka A (2005a) Temperature response rates in long-term phenological records. Clim Res 30: $21-28$

Menzel A, Sparks TH, Estrella N, Eckhardt S (2005b) 'SSW to NNE' - North Atlantic Oscillation affects the progress of seasons across Europe. Glob Change Biol 11:909-918

Menzel A, Sparks TH, Estrella N, Koch E and others (2006) European phenological response to climate change matches the warming pattern. Glob Change Biol 12: 1969-1976

Menzel A, Estrella N, Heitland W, Susnik A, Schleip C, Dose V (2008) Bayesian analysis of the species-specific lengthening of the growing season in two European countries and the influence of an insect pest. Int J Biometeorol 52:209-218

Mitchell TD, Jones PD (2005) An improved method of constructing a database of monthly climate observations and associated high-resolution grids. Int J Climatol 25: $693-712$

Oke TR (1973) City size and urban heat island. Atmos Environ $7: 769-779$

Rötzer T, Chmielewski FM (2001) Phenological maps of
Europe. Clim Res 18:249-257

> Rötzer T, Wittenzeller M, Haeckel H, Nekovar J (2000) Phenology in central Europe-differences and trends of spring phenophases in urban and rural areas. Int J Biometeorol 44:60-66

Root TL, Price JT, Hall KR, Schneider SH, Rosenzweig C, Pounds JA (2003) Fingerprints of global warming on wild animals and plants. Nature 421:57-60

Rosenzweig C, Karoly D, Vicarelli M, Neofotis P and others (2008) Attributing physical and biological impacts to anthropogenic climate change. Nature 453:353-357

Schönwiese CD, Staeger T, Trömel S (2006) Klimawandel und Extremereignisse in Deutschland. Deutscher Wetterdienst (DWD) 7-17, Klimastatusbericht 2005

Sparks TH, Menzel A (2002) Observed changes in seasons: an overview. Int J Climatol 22:1715-1725

Walkovszky A (1998) Changes in phenology of the locust tree (Robinia pseudoacacia L.) in Hungary. Int J Biometeorol 41:155-160

> Walther GR, Post E, Convey P, Menzel A and others (2002) Ecological responses to recent climate change. Nature 416:389-395

> Zhang XY, Friedl MA, Schaaf CB, Strahler AH, Schneider A (2004) The footprint of urban climates on vegetation phenology. Geophys Res Lett 31:L12209, doi:10.1029/2004GL 020137 
Appendix. 1. Histograms of temperature response $\left(\mathrm{d}^{\circ} \mathrm{C}^{-1}\right)$ of groups of phases classified by the regression coefficient and subdivided into the different regions; $n$ : number of series for each region (see Table 2 for latitudinal grouping of stations). $y$-axis: relative frequency $(\%)$. (square columns) Negative regression coefficients, (round pillars) positive regression coefficients, and (pyramids) 0 as class mean
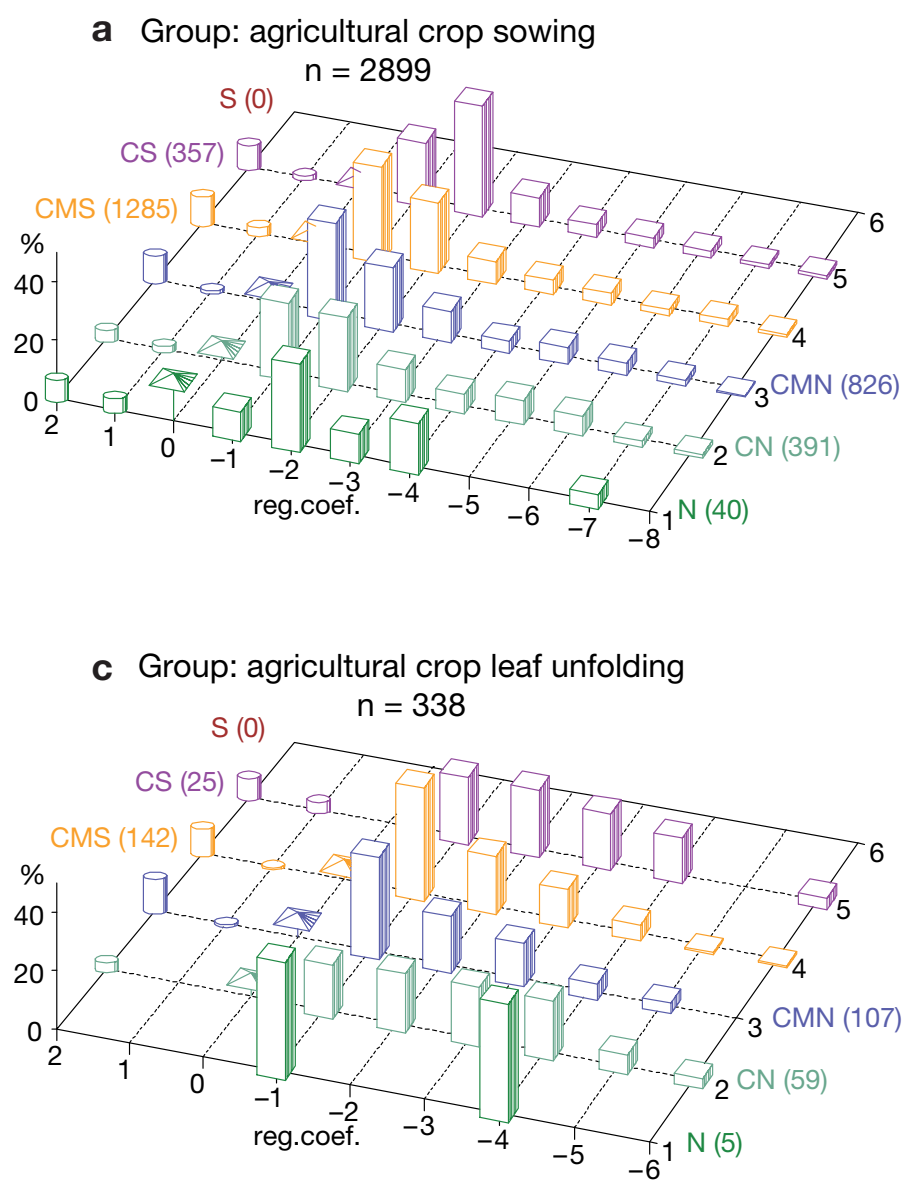

e Group: permanent grassland harvest

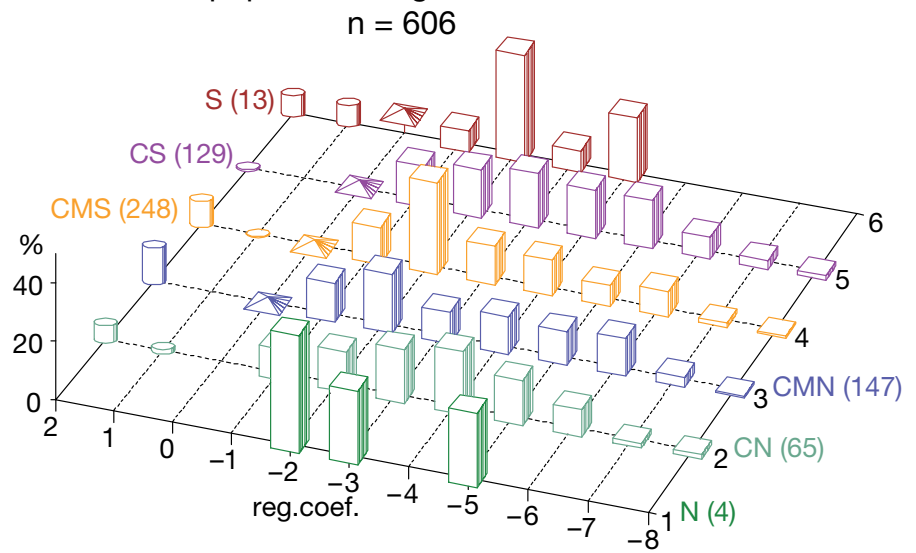

\section{b Group: agricultural crop growth stages}
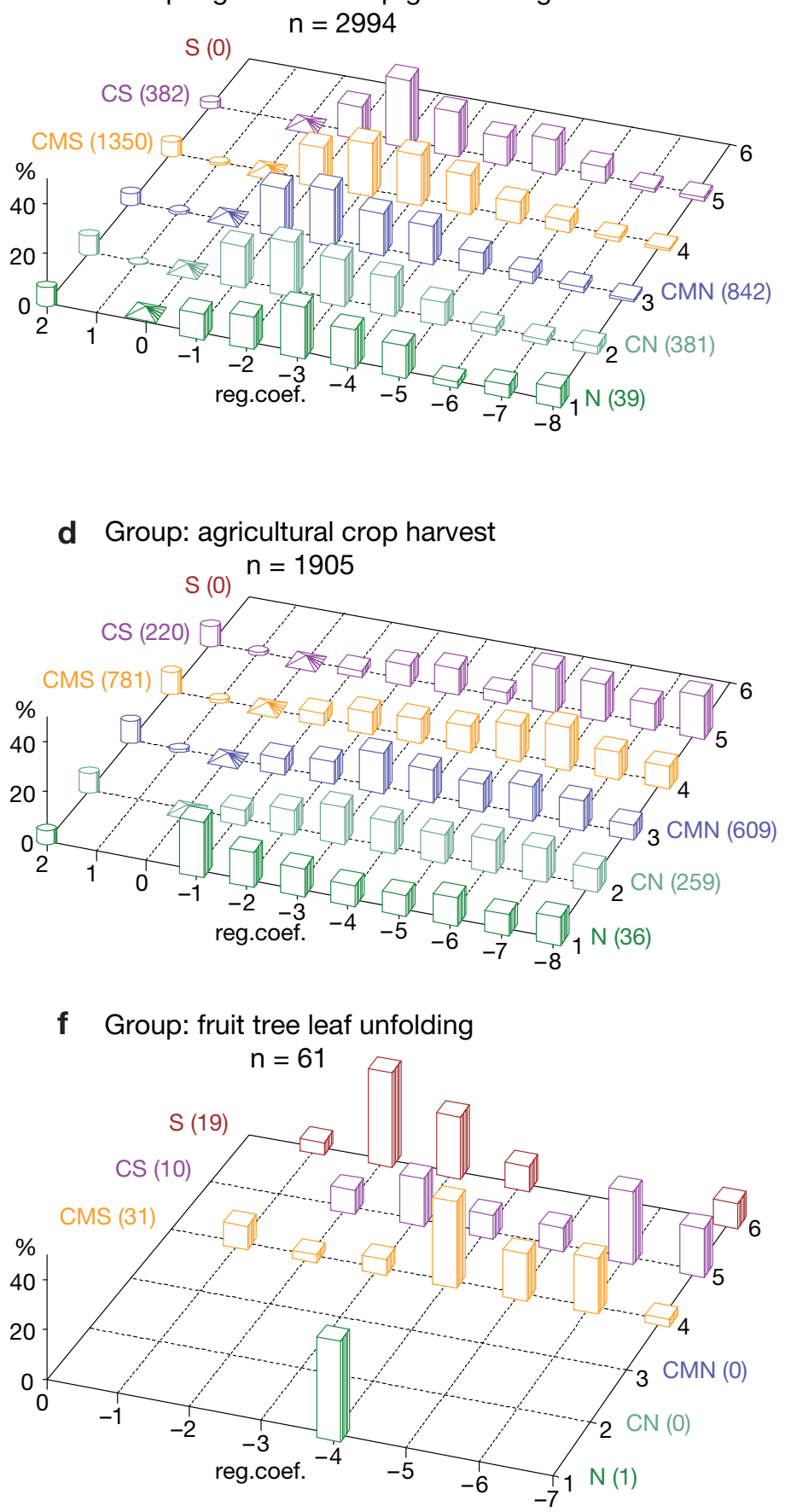
Appendix. 1 (continued)

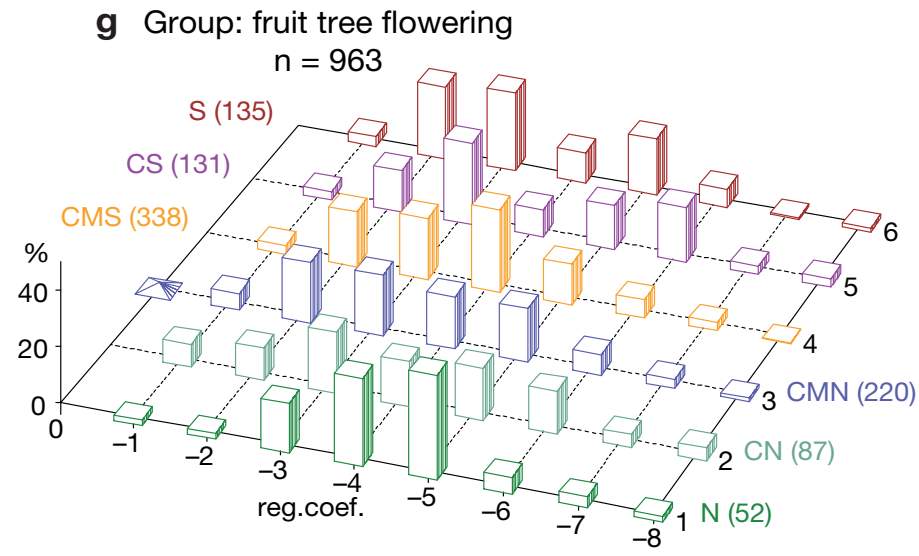

i Group: deciduous tree leaf unfolding $n=4139$

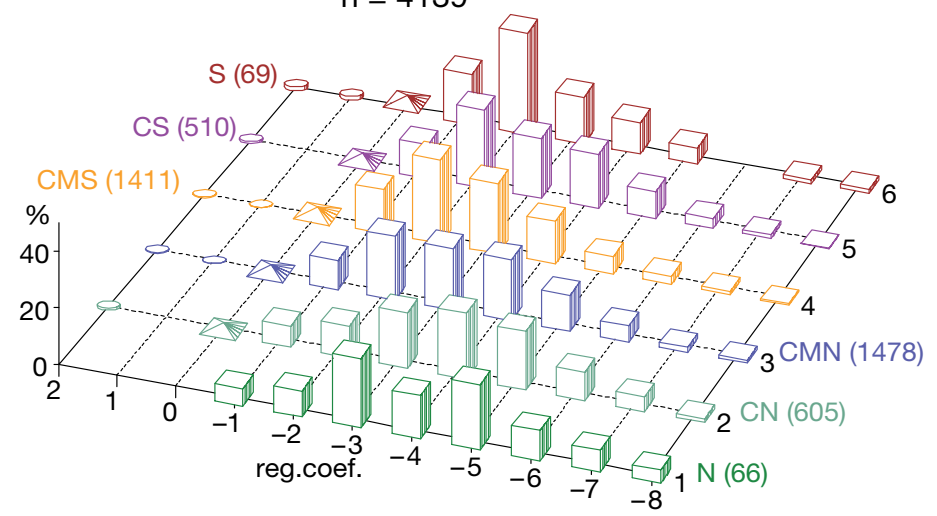

k Group: deciduous tree fruiting $\mathrm{n}=2693$

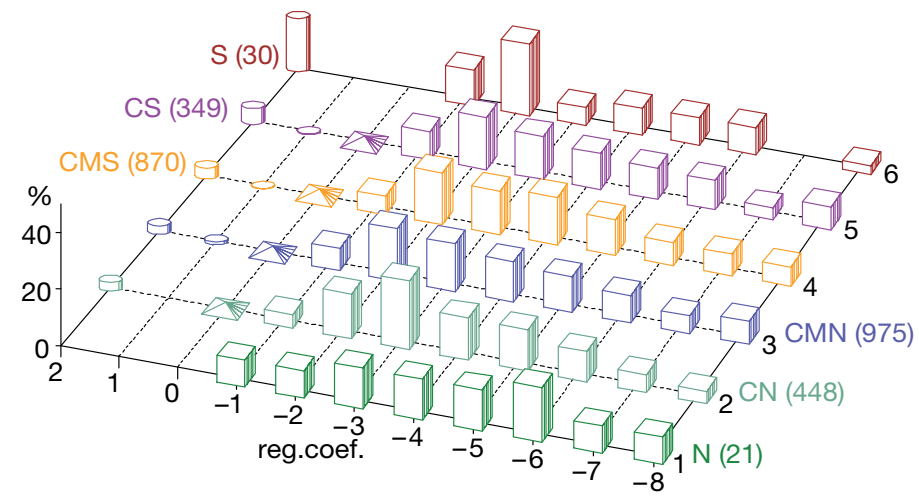

m Group: conifer needle development $\mathrm{n}=1252$

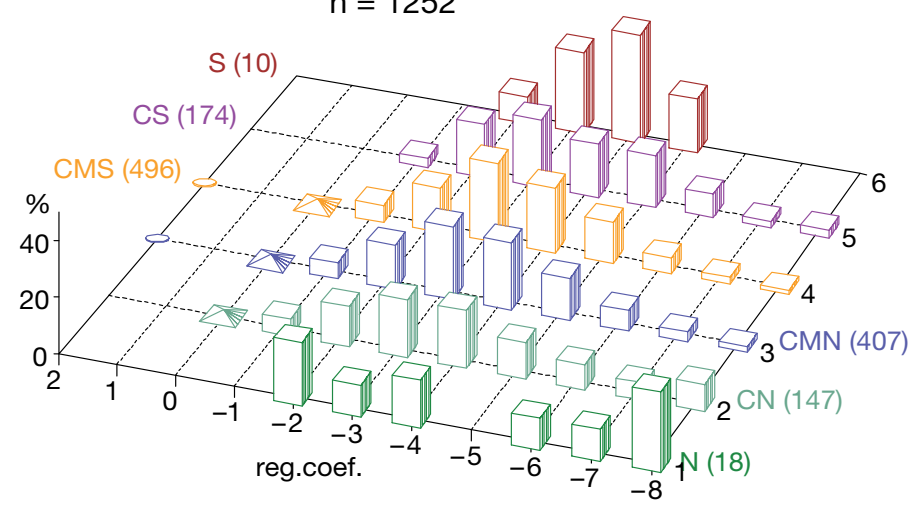

h Group: fruit tree fruiting $\mathrm{n}=2042$ $\mathrm{S}(0)$

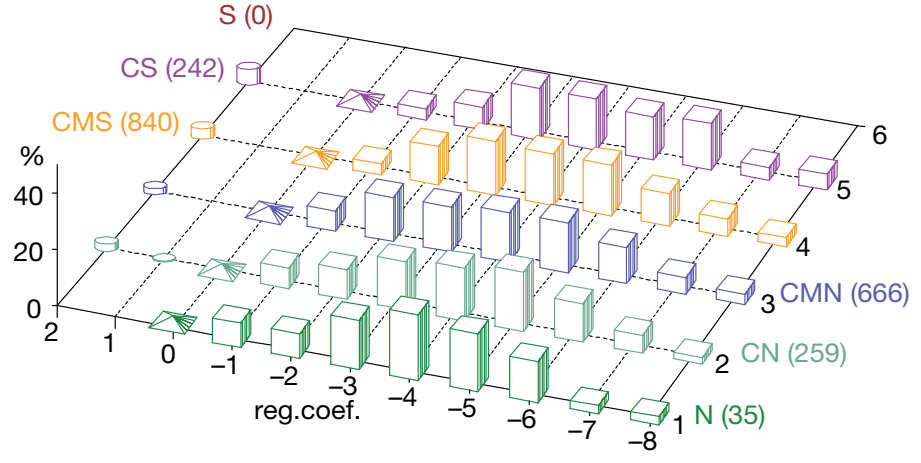

j Group: deciduous tree flowering $\mathrm{n}=7910$
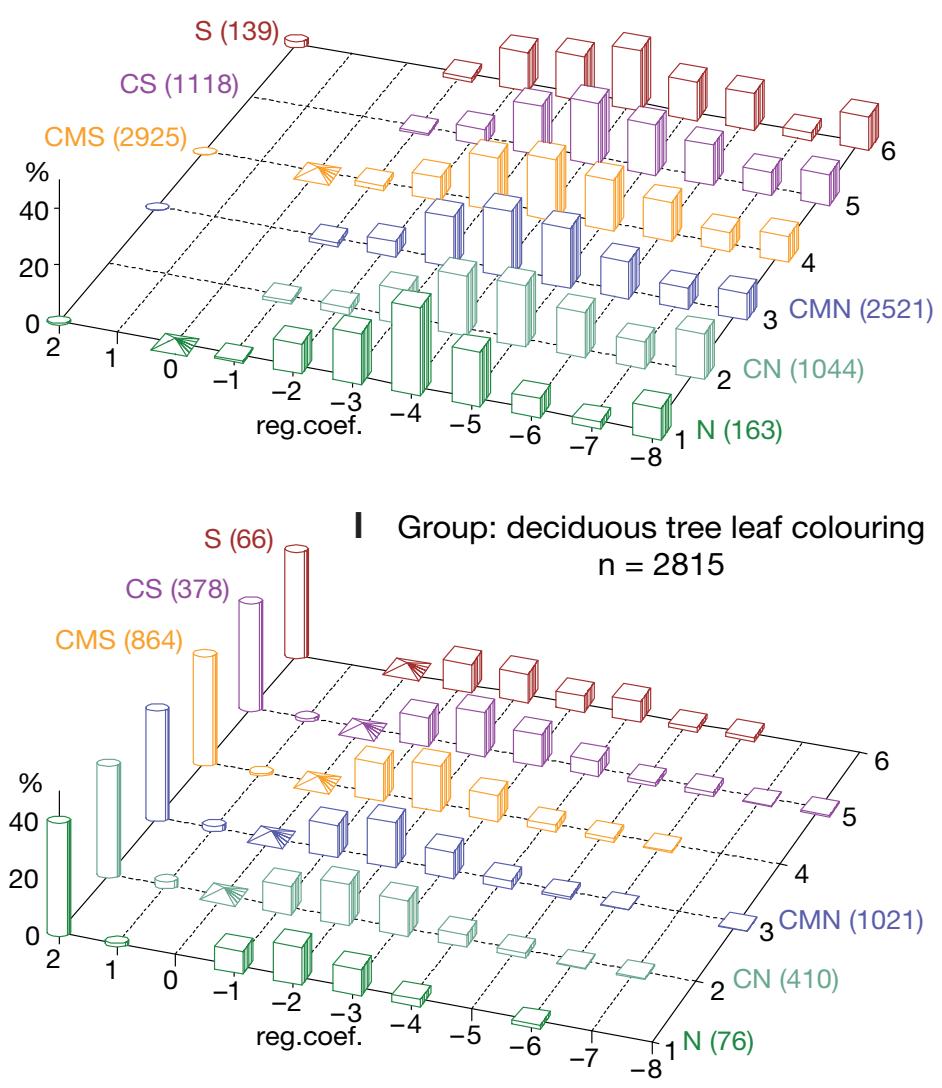

n Group: wild shrub / flower flowering $\mathrm{n}=3996$

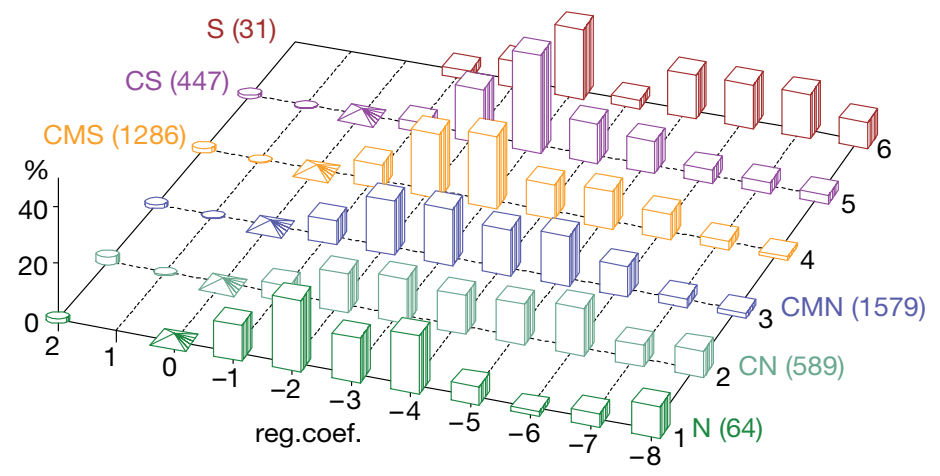




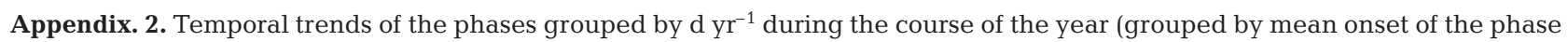
for the station). See Appendix 1 for definitions

a Jan-Jun

Jun (2742)

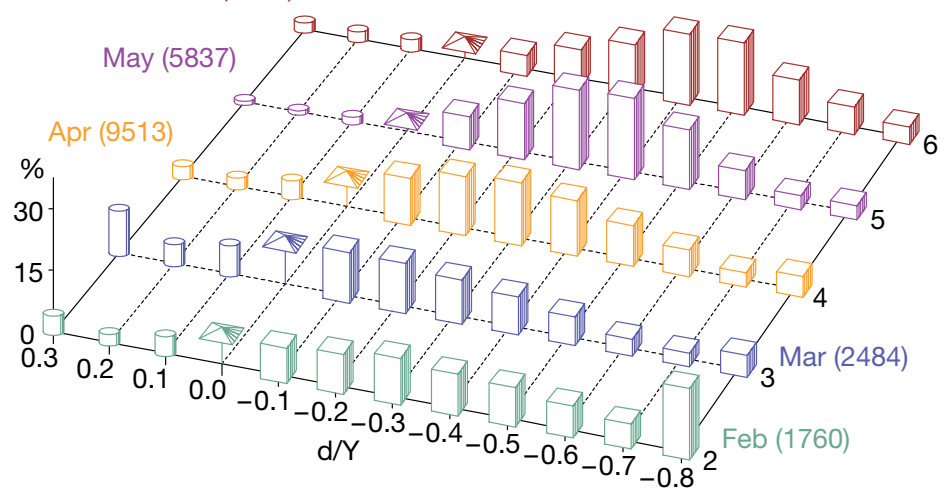

Submitted: December 4, 2008; Accepted: May 28, 2009

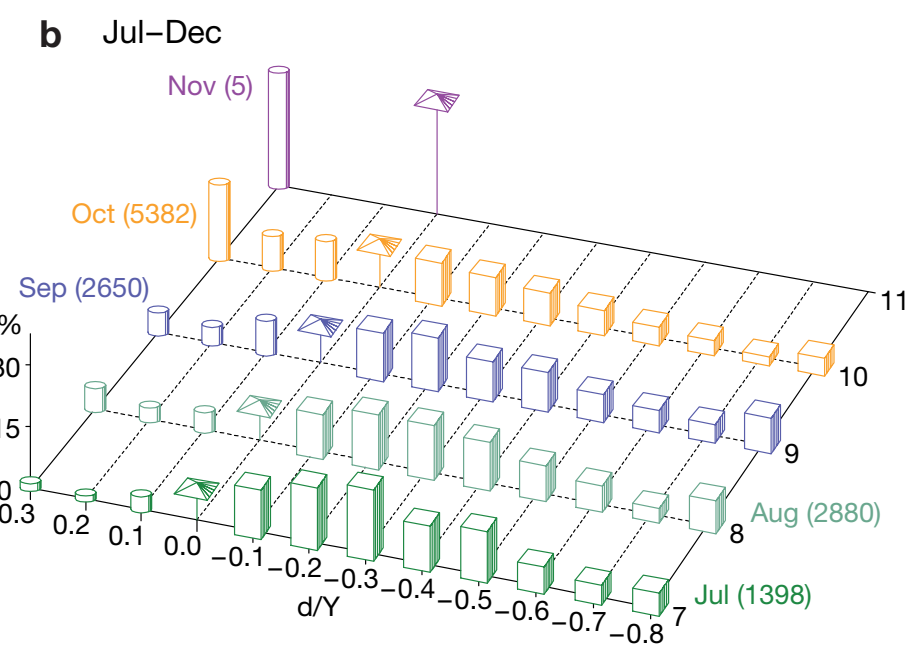

Proofs received from author(s): August 26, 2009 